\title{
The Place of an Institution of Higher Pedagogical Education in the Modern System of Mathematical Education in Russia in the Context of the Concept of Mathematical Education Development in the Russian Federation
}

Anvar N. Khuziakhmetov

Kazan (Volga region) Federal University, RUSSIA

Mihail V. Ladoshkin

Mordovian State Pedagogical Instittute, RUSSIA

Uljalgas A. Esnazarova

Al-Farabi Kazakh National University, KAZAKHSTAN

•Received 17 June $2015 \bullet$ Revised 22 August $2015 \bullet$ Accepted 19 September 2015

The relevance of the issue considered in the article is substantiated by the fact that at the present stage of mathematical education system development in Russia, there are active discussions concerning the necessity to maintain some institutions of higher pedagogical education. This is in order to provide the opportunity to implement innovative policy in the education system, and to train their graduates in compliance with the requirements for modern society experts in the field of mathematics. The objective of the article is to describe the possibilities of small institutions of higher pedagogical education to realize basic provisions of the Concept of mathematical education development in the Russian Federation. The leading research method of the designated issue is the method of results analysis and modeling of development prospects of a higher education institution, making it possible to transfer the positive experience of the Concept implementation in Mordovian State Pedagogical Institute into the practice of another higher education institution activity. The article represents the ways that Mordovian State Pedagogical Institute, as a typical institution of higher pedagogical education, applies to solve the main problems in the field of general and vocational education declared in the Concept; the major results obtained in the implementation of the Concept provisions; and, proposed guidelines for further development within the context of the Concept implementation.

Correspondence: Mihail V. Ladoshkin,

Mordovian State Pedagogical Instittute, 13, Studencheskaya Street, Saransk, 430000, Russia.

E-mail: m01051977@mail.ru

doi: 10.29333/iejme/299 
The materials of the article may be useful for teachers of mathematics at institutions of higher pedagogical education as a perspective plan aimed to achieve positive results for mathematical education development in a higher education institution.

Keywords: mathematical education, institutions of higher pedagogical education, mathematical enlightenment, monitoring, methods of teaching mathematics.

\section{INTRODUCTION}

\section{The research relevance}

Modern mathematical education in Russia is an apparent heir of the Soviet mathematical school traditions that were created in the second half of the last century and reached its greatest heights in the 1970-80s. These years were the period when the achievements of Soviet mathematicians in the field of geometry, topology, functional analysis, and the theory of management were widely recognized by the world scientific community, despite the closedness of Soviet society at that time. Soviet school children regularly took part in international mathematical Olympiads and won first prizes,often leaving other participants far behind. The progress of Soviet education in the field of mathematical and natural sciences was recognized around the world, and many countries started copying this system. However in the final decade of the last century, the general crisis within the country affected mathematics education as well. Though fundamental developments of Russian scientists were still highly appreciated in the world (citizens of Russia several times received theFields's award between 1994 and2014), at the same time school mathematical education experienced a recession that resulted in failures at international competitions of mathematicians; only once in the 21st century have they managed to win against the national team of China (Podreiko, 2002).

The existing situation was considered by the Russian authorities, and as a result, along with the program of pedagogical education development in Russia, there was adopted the Concept of mathematical education development in the Russian Federation (hereinafter - the Concept) which represents "the system of ideas concerning basic principles, goals, tasks and guidelines of mathematical education development in the Russian Federation". The Concept declares the special place of mathematics in science and culture; it approves the need of quality mathematical education for successful life of each individual in the modern society. The Concept also determines the importance of mathematics and mathematical education in the planned modernization of the economy, its transfer to innovative ways of development, solutions of social and economic tasks. The Concept admits considerable achievements of the Soviet education system and offers to save its advantages and overcome drawbacks. At the same time there should be noted the Concept's declarative character; it is not backed up by any standard or regulatory acts. Nevertheless, this very document determines the activity of state educational institutions in the sphere of mathematical education.

Over the last years various discussions about the place and role of institutions of higher pedagogical education in the education system in general (Kadakin\&Shukshina, 2013), and in the system of mathematical education in particular (Sarancev, 2014) have taken place. The teacher of a higher education institution in modern society is positioned as the manager in the field of educational services, and that implies areorganization of consciousness and methods of work (Zeleeva\&Gyurova, 2014). The thesis that it is easier to carry out such changes within big educational centers has beenput forward; as a result there are tendencies to merge higher education institutions that, in turn, often leads to the situation whereclassical universities or technical colleges absorb institutions of higher pedagogical education. The objective of this article is to show the ways of mathematical education modernization in an 
institution of higher pedagogical education, in the context of Mordovian State Pedagogical Institute activity. The given research is urgent in regard to the situation with institutions of higher pedagogical education in Russia in general, and especially with the role which is currently assigned to mathematical education by the nationalauthorities.

\section{METHODOLOGICAL FRAMEWORK}

\section{Research methods}

In the course of the research, the following research methods were applied: analysis of regulative documents and products of activity, method of mental experiment, forecasting, systematization and generalization of facts and concepts, method of expert evaluations, and the analysis of monitoring results of students' knowledge acquisition and mastering.

\section{Research experimental base}

MordovianStatePedagogical Institute named after M.E. Evsevyev (hereinafter named - pedagogical institute) is a typical example of provincial institutions of higher pedagogical education, with a rather small studentbody (about five thousand) and a small teachingstaff (about 350). The main direction of training in the pedagogical institute is "Pedagogical education" (about 80\% of students) according to various profiles (generally combined). The survey and results are given for the period from 2010 to 2015, i.e. they cover the period before the adoption of the Concept, and throughout the period of its implementation in a higher education institution. It should be noted that the Republic of Mordovia is not a large scientific center in the field of mathematics; therefore, it is possible to consider the results of this higher education institution research activity in the field of mathematical education system development in the region as a strategy for other similar regional pedagogical institute's development.

\section{RESULTS}

\section{Description of problems structure and answers to them}

The following basic groups of mathematical education development issues in Russia are singled out in the Concept:

- issues of motivational character

- issues of content character

- human resources issues.

Let us consider the issues of the first group. Students' and school children's low educational motivation is connected with public underestimation of mathematical education importance. In the case of students studying atinstitutions of higher pedagogical education, there are added issues of school teachers' activity motivation (Kalatzkaya, Kostyunina,\&Drozdikova-Zaripova, 2014). To make students of Mordovian State Pedagogical Institute understand the importance of mathematical education, the content of the discipline "Foundations of mathematical information processing" is being worked out. This discipline is an obligatory component of the natural-science and mathematical block of disciplines included in FGOS in the direction of "Pedagogical education", and is the only academic subject forming mathematical competence at the majority of faculties of higher education institutions. This discipline content meets the requirements important for the processing of pedagogical experiment results that is a necessary condition to carry out research for a graduation thesis. In comparison with the discipline "Mathematics", which was 
earlier included in the curricula of many pedagogical specialties, it enhances the practical component; the realization of algorithms and tasks arecarried out with the help of computers (Ladoshkin\&Derbedeneva, 2013). The fact that additional vocational programs on mathematics were chosen by $86 \%$ of students $(12 \%$ of those who studied the subject "Foundations of mathematical processing of information" in 2013) trained at non-mathematical specialties testifies that students have increased their motivation for studying mathematics and improved their level of mathematical competences Thus, practically every eighth student after studying this discipline realized the importance of mathematics and made an independent conscious decision to increase the competence in this area of knowledge.

The motivation of students trained at the physical-mathematical faculty of the pedagogical institute positively influences the motivation of students in general. According to the survey of the higher education institution quality management system, about $90 \%$ of students do not change their choice of training profile. The motivational component at the faculty of psychology and defectology is expressed in the uptakeof the subject "Mathematics and mathematical statistics" by practicefocused content (Ryabina, 2003).

Let us consider the issues of mathematical education content. As for higher pedagogical education, the main problem is the isolation of disciplines content from practice, from a real situation in preschool and comprehensive education system. This problem is recognized as one of the most significant at the institute, and considerable attention is being paid to a solution. Almost all members of the mathematics department are involved in the work of the physical-mathematical school "Kvant"; this school is a part of the Small School Academy created in the pedagogical institute. The teachers have the opportunity to improve their techniques of teaching mathematics in the context of a real school; besides they may quickly react to the demand and needs of educational services consumers. Teachers' own staff members of the faculty of pedagogical and art education, where future primary school teachers and employees of preschool education system are trained, carry out their activity within an innovative structure - the after-school Center attached to the Mordovian State Pedagogical Institute. Asits basis, new approaches to mathematical and logical education are being introduced into the system of preschool and primary school education (Maslova\&Dubova, 2013). Such practice allows teachers to deal more actively with issues of preschool mathematical education, to consider theoretical questions in direct connection with practical work in preschool education institutions (Petrova, 2014). Teachers at theMordovian State Pedagogical Institute annually participate in the assessment of Unified State Examination works on mathematics; to carry out this work they are trained and their skills are tested in "The center of monitoring and assessment of education quality" located in Saransk.

The system of interaction with regional and city methodical associations of mathematics teachers is organized atthe institute. Thus, teachers have the opportunity not only to consult school teachers about various questions concerning techniques of teaching mathematics, but also to state problems which mathematics teachers face in their daily activity. Such consultations result in academic subjects content improvement, e.g. "Methods of teaching mathematics" and elective courses as well. The collaboration with school teachers, arrangement of consultations, consideration of arising questions find their reflection in scientific researches of the leading faculty staff (Kapkaeva, 2012). The similar work is conducted with primary school teachers; in addition, teachers of Mordovian State Pedagogical Institute take part in consultations of preschool educational institutions employees.

As for the issues concerning the content of higher vocational education, it is possible to note that adopted Federal state educational standards of higher vocational education of the generation "three plus" do not identify mathematics as an obligatory academic discipline even for technical specialties; it is a higher education institution 
that should take decisions on this matter. In practice such an approach often leads to the reduction of test units and classroom time preparation for mathematics. The consequence of such approach is not only the deterioration of students' mathematical training level, but also the decrease of a higher education institutions personnel capacity on mathematics. On May 25, 2015 there was a meeting held of the Scientific and methodical council for mathematics in Moscow, where the issue "New Educational Standards (FGOS-3+) in the context of the Adopted Concept" was discussed. The representatives of the Ministry of Education of the Russian Federation participating in the meeting pointed out that higher education institutions are responsible for the management of graduates' mathematical training; there, it was also announced that the monitoring of its compliance with employers' requirements should be carried out. When issues of curricula are discussed, the Academic Council of the institute always states the necessity to improve students' mathematical training (it concerns non-specialized profiles) by inclusion of elective courses of a mathematical orientation in the curriculum (Ladoshkin, 2012).

It is directly specified in the Concept that isolation of mathematical education in higher education institutions from modern science and practice results in adecrease of education level. In this connection Mordovian State Pedagogical Institute collaborates with MCSU, named after Sholokhov, within the interaction network to test curricula for mathematics teachers. In 2015, the work was conducted to test pedagogical institutes' curricula and discipline compliance, with the requirements of a higher education institution developer. There was an active process aimed to exchange opinion about the content of disciplines, the necessity to include these or those sections into them, and the compliance of competences offered by higher education institution developer with the requirements of the state educational standards. The correlation of curricula content with the possibilities of a higher education institution makes the main problem of working out programs according to the standards of generation 3+ that have not been adopted, yet thus preventing their introduction into the educational process. Besides, in the programs of higher education institution development, there is a unification of teachers' professional standards in which competences mastering is realized by means of specified educational (labor) actions. This approach is supposed to be realized further in programs of disciplines in Mordovian State Pedagogical Institute as it provides complete mathematical training on the basis of activity approach. The contract on network interaction is concluded between higher education institutions; within this contract it is supposed to unify the main educational programs for the same trainingprofiles, enabling students to easily change the trajectory of training and/or higher education institution. The end of 2015 is designated as the final stage of testing. According to the testing results, the Ministry of Education and Science will be offered a joint version of the "Subject Training" and "Methods of Teaching Mathematics"programs modules. About 20 teachers from the Mordovian State Pedagogical Instituteimproved their vocational skills, according to the programs of academic mobility in the field of mathematical education and design of educational programs.

There is a thesis committee (D 212.118.01) attached to the Mordovian State Pedagogical Institute where doctoral and Ph.D theses in the specialty 13.00 .02 Theory and methods of training and education (mathematics at a comprehensive and higher school) are maintained. The chairman of this council is the doctor of pedagogical sciences, and the corresponding member of the Russian Academy of Education is Professor G.I. Sarantsev. In recent years the number of theses maintained by school teachers has increased (in 2014-15, two out of five theses were maintained by school teachers). All works are discussed at the scientific-methodical seminar "Problems of teaching mathematics in a higher education institution and school" (the 
head of the seminar is the doctor of pedagogical sciences, Professor I.V. Egorchenko). Such work allows members of mathematics and methods of teaching mathematics department, together with the teachers' staff of the Mordovian State Pedagogical Institute, to follow modern developments in the area of mathematical education. This practice corresponds to modern views on teacher's research activity (Biktagirova\&Valeeva, 2014; Kapkaeva, 2013).

Issues of human resources in mathematical education are stated as urgent in the Concept. Currently, according to the Concept, the training obtained by a vast majority of students in mathematics and pedagogical specialties does not promote intellectual growth or, more importantly, does not meet the requirements of pedagogical activity. The distinctive feature of an institution of higher pedagogical education in the field of mathematics teachers' training, is that along with mathematical education of graduates we train future teachers who will reproduce mathematical education at various levels of comprehensive education (Vlasova, Kirilova, \& Sabirova, 2015).

The system of monitoring is widely used in the Mordovian State Pedagogical Institute to determine the level of mathematical training. The external monitoring of the training direction "Pedagogical education" is characterized by the fact that higher education institutions' developers have no test materials on the discipline "Foundations of information mathematical training". Nevertheless, monitoring at all levels - chairs, dean's offices, and education management - takes place in the pedagogical institute. Test and measuring materials are developed by the chair without the involvement of leading teachers, but with the use of their curricula. The procedure of monitoring and assessment of results is also separated from the leading teacher in order to provide independence. Similar work is carried out at the faculty of psychology and defectology; there, students' mathematical competence is developed within such disciplines as "Mathematics" and "Mathematical statistics". This work brings successful results of monitoring at various levels, including external monitoring FEPE on the disciplines that were monitored within the frames of preparation for the institute accreditation at the end of 2014. According to the results of FEPE, external testing in "Mathematics" showed the level of academic disciplines mastering increased from $70 \%$ to $75 \%$ with a threshold level of $60 \%$.

At the same time, results of monitoring cannot completely reflect the level of mathematical competence development. In general it may be connected with the imperfection of test and measuring materials (the Concept directly specifies this fact). Besides, test and measuring materials for monitoring are created to meet the requirement to check the level of discipline mastering. The issue of discipline content compliance with the requirements of modern education is not taken into consideration. To solve this problem, those school teachers who have great practical experience deliver disciplines of vocational training at the Mordovian State Pedagogical Institute. These teachers represent lyceums specialized in mathematics and natural technical sciences. Elective courses are taught by these teachers on the basis of lyceums in the city of Saransk. Within these courses, students are prepared for future school practice. Besides, students participate in the work of courses aimed to train to solve Olympiad tasks on the basis of lyceums No. 4 and No. 43 of Saransk city; they work with school children during special mathematical weeks and help to prepare research works and projects.

\section{Main directions of the Concept implementation}

The following directions aimed to implement the Concept are singled out by the authors: 
In preschool education - creation of conditions for preschool children to develop forms of activity, primary mathematical representations and images used in life. Students of Mordovian State Pedagogical Institute are trained to realize these skills on the basis of the after-school Centre in which the most perspective and innovative methods of training, including the program "School-2100", are applied.

In primary comprehensive education - to provide a wide range of mathematical activity trained both duringlessons, and in extracurricular activities. To realize these tasks new elective courses are developed forthe corresponding profiles of training; it allows students to create information and material conditions to develop learners by means of mathematics (Yankina, 2013).

The Concept pays special attention to the opportunity ofachieving compliance of any level of training with schoolchildren's individual needs and abilities within basic general and secondary education. Thus, the revision of curricula to meet the standards plays an important role (Sarancev, 2013). Individualization of training, creation of individual trajectories of training depending on schoolchildren abilities and needs are considered within the academic subject "Methods of teaching mathematics". Students apply both information means, and modern opportunities of distance and electronic learning to design such trajectories (Skornyakova, 2014).

The interaction of teachers of mathematical chairs with schools has to play a significant role in professional education. Besides the aspects considered above, the Mordovian State Pedagogical Institute facilitates the preparation of study guides for teachers and school children. In particular, the works of Sarantsev (2013), Kapkaeva $(2012,2013)$ et al. are worth mentioning. School practice is considered by the Concept as one of the indispensable conditions of students' vocational training. Such practice is provided by the curricula of the Mordovian State Pedagogical Institute in compliance with the standards of "Pedagogical education" direction. Besides, the curriculum adopted at the physical and mathematical faculty in the profile "Informatics. Mathematics" (applied bachelor degree) provides students' with extended school practice in the eighth and ninth terms (third course).

It is necessary to note the work of the institute in the sphere of additional vocational education, mathematical sciences and the training of scientific and pedagogical workers aimed at implementing vocational advancement programs in the field of mathematical education. Eight vocational advancement programs for various population groups are currently being realized. In general, these are for students of the institute who want to obtain additional data on mathematics, or specific data and methods of teaching for their vocational activity. Programs that are focused on the study of higher mathematics applications are in great demand as they are used to solve tasks associated with school courses. Advanced vocational programs at the physical and mathematical faculty involve about $40 \%$ of students; it is a good indicator testifying to students' interest in the improvement of their mathematical competence.

Speaking about the development of mathematical science itself at the Mordovian State Pedagogical Institute, it should be noted that during the period from 2010 to 2013 there were four projects implemented within the Federal Targeted Program "Scientific and Academic Specialists for Innovative Russia". According to the results of the research within these projects, there were two Ph.D. theses. Students also took part in the implementation of these projects; some of them continued their training at postgraduate courses in the specialty 05.13.18 "Mathematical modeling, numerical methods and complexes of programs"; and now they have gone on to conduct teaching activities.

The important direction of mathematical education development, according to the provisions of the Concept, is mathematical education and the promotion of mathematics. To realize this provision, there are annual open Olympiads arranged on 
various subjects, including mathematics. In 2015, more than 1,200 school children of grades 7-11 from the city of Saransk, regions of the republic, and from Nizhny Novgorod, Ulyanovsk, Samara, and Penza areas took part in the mathematicsOlympiads. In 2015, the institute submitted the application to include the open Olympiad on mathematics in the list of Olympiads approved by the Ministry of Education and Science of the Russian Federation, as this grants privileges for the enrollment in higher educational institutions. In March 2015,the Mordovian State Pedagogical Institute held the festival "Days of Science in the Republic of Mordovia"with the support of the Dmitry Zimin's Fund, "Dynasty". During the festival lectures were delivered by scientists-mathematicians, school teachers and winners of the "Dynasty" fund; there was also a meeting held for the methodical association of teachers. The festival lasted three days, and it was widely written about in the media, with bothparticipants and organizers enjoying this event. The Festival events resulted in an increased number of those interested in entering the physical and mathematical faculty. Unfortunately, the festival arrangement is doubtful for 2016 due to some problems the Fund is experiencing.

One more form of mathematical education is the project known as "School Saturday", prepared by the Mordovian State Pedagogical Institute. Every Saturday, teachers of the institute meet with school children, and lectures on mathematics and consultations on the solution of tasks are offered within this project are traditionally popular. To arrange extra-curricular activity for students studying at the physical and mathematical faculty,a circle has been created with members focused on the solution of Olympiad tasks in the area of higher mathematics. Participants of the circle regularly take part in International Internet Olympiads. On May 24-25, 2015,a student of the $3 \mathrm{~d}$ course TouzhilkinaAlena participated in the in-person round in Ioshkar-Ola, according to the results of the try-out round. She was awarded the laureate diploma and the nomination "A Wise Head of the Olympiad". Annually the institute holds Olympiads for students to select the best for Olympiads of various levels. The physical and mathematical faculty collaborated with the educational portal A2-B2 which exercises methodical support of mathematics teachers in respect of providing them with multiple standard tasks for test works and individual homework.

\section{DISCUSSIONS}

The place of higher education institutions in the modern education system has been discussed a lot and from various points of view (Biktagirova\&Valeeva, 2013; Ganieva et al., 2014). The issue of mathematical education quality in modern Russia was studied by many researchers, in particular, Arnold (1999) was the first to raise this issue; his article formed the basis of many provisions in the Concept. The issues of mathematical education were discussed by former Ministers of Education and Science of the Russian Federation. Many researchers wrote about the need to preserve some pedagogical institutes (Kadakin\& Shukshina, 2013).However there has beenno research considering the ways aimed to implement the Concept of mathematical education itself, or the place of pedagogical institutes as regional centers of general education. The results given in this work are authentic and havenot been previously published to the wider scientific community. All this testifies to the novelty and scientific importance of the presented work.

\section{CONCLUSION}

The presented article substantiates the idea that the institution of higher pedagogical education may be quite successful in the sphere of mathematical education. It is shown that the appropriate planning makes it possible to achieve positive results even if the institution 
of this type is not large and has limited teaching staff. There main areas of work in which specialists in the field of mathematics and the methods of its teaching have to focus are implementingtasks in the sphere of mathematical education in the country and to promote Russia in the modern world. The role of various innovative structures created on the basis of the institution of higher pedagogical education is significant (Suharev, Maslova, \& Naumova, 2012).

\section{RECOMMENDATIONS}

The results presented in the article may be useful for teachers of mathematical disciplines of the institutions of higher pedagogical education as an example of successful existence in the context of new educational standards, updating of the educational system in general, and formathematics in particular. Without exaggeration, the results achieved by the Mordovian State Pedagogical Institute, named after M.E. Evsevyev, testify to the fact that it has gained the right to enter the list of the most successful Russian higher education institutions, and to be among the first ten institutions of higher pedagogical education.

\section{REFERENCES}

Arnold, V. (1999). Polymathematics: is mathematics a single science or a set of arts? Mathematics: frontiers and perspectives American Mathematical. Society, RI, 403-416.

Biktagirova, G.F.,\&Valeeva, R.A. (2013). Technological approach to the reflection development of future engineers. 16th International Conference on Interactive Collaborative Learning, ICL, 2013 (pp. 427-428). Kazan, Russian Federation: Kazan National ResearchTechnological University.

Biktagirova, G.F.,\&Valeeva, R.A. (2014). Development of the teachers' pedagogical reflection. Life Science Journal, 11(9s), 60-63.

Ganieva, Y.N., Azitova S.G., Chernova, Y.A., Yakovleva, I.G., Shaidulina, A.R.,\&Sadovaya, V.V. (2014). Model of high school students professional education. Life Science Journal, 11, 504-509.

Kadakin, V.V.,\&Shukshina, T.I. (2013). Pedagogical University as a basic teacher's training center. Higher Education in Russia, 4, 60-68.

Kalatzkaya, N.N., Kostyunina, N.I. \&Drozdikova-Zaripova A.R. (2014). Motivational peculiarities of schoolteachers in Russia. Life Science Journal, 11, 243-247.

Kapkaeva, L.S. (2012). Algebraic and geometric methods in the school course of mathematics as ways of cognitive activity of students. The Humanities and education, 1, 18-22.

Kapkaeva, L.S. (2013). The formation of the methodical skills of future teachers of mathematics in learning mathematics. Problems of modern education, 4, 162-170.

Ladoshkin, M.V. (2012). The problem of accounting of competences within FSES-3. Kazan Science, 9, 228-231.

Ladoshkin, M.V.,\&Derbedeneva, N.N. (2013). Constructive analysis of the experience of implementing the discipline "Mathematical Foundations of information processing in educational process of pedagogical higher education institution.The Humanities and education, 3, 28-32.

Maslova, S.V.,\&Dubova, M.V. (2013). Competency-based task as a means of achieving educational effects in the primary classroom. The Humanities and education, 1, 18-23.

Petrova, V.F. (2014). Singularities of preschool mathematical education in Russia. Life Science Journal, 11, 492-496.

Podreiko, A.M. (2002).School mathematics from the point of view of University Math in school, 2, 77-78.

Ryabina, N.O. (2003).What the psychologist is mathematics? Matematica in higher education, $1,63-65$.

Sarancev, G.I. (2013). Harmonization of the methodological training of bachelors of pedagogical education. Pedagogika, 3, 59-66.

Sarancev, G.I.(2014). Teacher - modern teaching thinking. Science and school, 2, 12-16. 
Skornyakova, A.Y. (2014). Construction of information and communication of the subject environment as a means of developing research competence of future bachelors of pedagogical education. Educational technology and society, 17, 23-26.

Suharev, L.A., Maslova, S.V.,\&Naumova, T.A. (2012). The use of innovative educational technologies in the professional training of teaching staff. The Humanities and education, 2, 18-23.

Vlasova, V.K., Kirilova, G.I.,\&Sabirova, E.G. (2015). Functioning of information educational environment: Meta dynamic approach. Review of European Studies, 7(5), 25-30.

Yankina, L.A. (2013). The activity of the teacher of higher school in the conditions of introduction of the GEF IEO. Elementary school plus before and after, 2, 17-20.

Zeleeva, V.P.,\&Gyurova, V. (2014). Competency model of university teacher as manager in education. Section of Education and Education Research, 3, 161-168. 